\title{
Measurement and verification of a lighting load reduction project through energy efficiency
}

\author{
Idah Masopoga \\ Christo van der Merwe
}

School of Mechanical Engineering, North West University, Potchefstroom

\begin{abstract}
This paper will describe the methodology and procedures that were followed to measure and verify the impact on the electricity use of a lighting load reduction project implemented at a gold mine. The lighting retrofit was concentrated on the 100 level and 100 incline of the gold mine. Since the lights were underground, it was operational for 24 hours each day. The proposed project activity aimed to reduce the electric demand of the lighting system by replacing the current types of lighting fixtures with more energy efficient units.

The possibility existed to reduce the lighting load by $157 \mathrm{~kW}$. These impacts needed to be assessed in order to verify the DSM impacts and savings for the client, the ESCO and Eskom. Pre-implementation metering was done in order to determine the operational and installed capacity of the original lighting system. Together with the number of lights affected by this project activity and the 24-hour operational profile, this data defined the baseline electricity use of the project. The same metering techniques and layout have been used after implementation to determine the new installed and operational capacity of the new lighting system. This project achieved $99.36 \%$ of its contracted target of $157 \mathrm{~kW}$.
\end{abstract}

Keywords: lighting efficiency retrofit, $M \& V$ of lighting retrofits, efficient lighting upgrade, $M \& V$ of EEDSM projects

\section{Introduction}

Eskom, the client, and the Energy Service Company (ESCO) all ask the same questions after an energy project has been completed: 'How much has been saved?' and 'Are the savings being sustained?'

Measurement \& Verification $(\mathrm{M} \& \mathrm{~V})$ is an external entity that is independent of the Demand-side Management (DSM) project, which ensures that these questions are answered in the most impartial and transparent way. To do this, the $\mathrm{M} \& \mathrm{~V}$ team should have an exact understanding of the project and its proceedings.

This paper will give an overview of the whole $\mathrm{M} \& \mathrm{~V}$ process that was followed during a lighting efficiency upgrade as well as the results. These results will then be compared to the expected results of the ESCO and the differences will be discussed.

\subsection{DSM project objective}

The objective of this project activity was to reduce the underground lighting load at a mine. There were 2395 underground lighting fixtures which were targeted for replacement. These lights were replaced with more energy efficient lighting fixtures. The ESCO has found that the lighting load is 295.9 $\mathrm{kW}$ before implementation. The possibility existed to reduce the lighting load by $157 \mathrm{~kW}$ as performed by the ESCO.

\subsection{Site description}

The gold mine is situated near Carltonville. The level on which the project will be implemented is about $100 \mathrm{~m}$ below surface and covers an area of around 14 square $\mathrm{km}$.

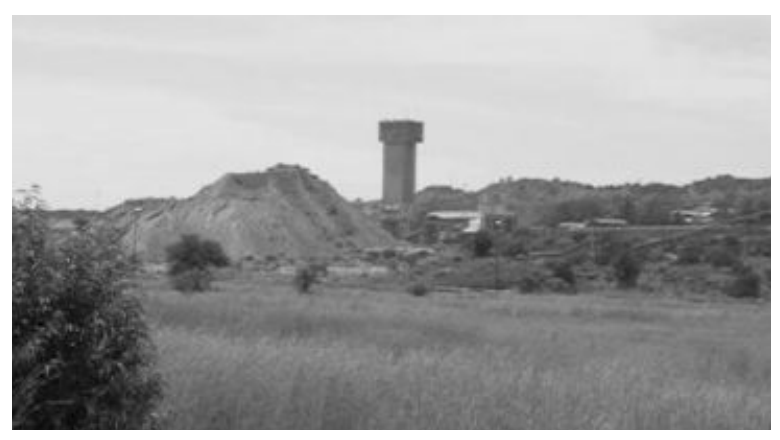

Figure 1: View of the mine

\section{Audit of lighting system}

The lights are in use 24 hours a day for 365 days of the year. The lighting system is made up of a num- 
ber of individual lines fed from gully boxes found at the side of the haulage. The gully boxes are provided with $110 \mathrm{~V}$ power. There were 2395 underground lighting fixtures, which were targeted for replacement. Table 1 shows the original and proposed lighting types.

Table 1: Original and proposed lighting types

\begin{tabular}{ll}
\hline Original type & \multicolumn{1}{c}{ Proposed type } \\
\hline $2 \times 8 \mathrm{ft} \mathrm{T12-75W}$ fluorescent & $2 \times 5 \mathrm{ft} \mathrm{T8-58W}$ fluorescent \\
\hline $60 / 100 \mathrm{~W}$ incandescent & $13 \mathrm{~W} \mathrm{CFL}$ \\
\hline $125 \mathrm{~W}$ mercury vapour & $24 \mathrm{~W}$ delux ECG \\
\hline $2 \times 5 \mathrm{ft}$ T12-65W fluorescent & $80 \mathrm{~W}$ fluorescent \\
\hline
\end{tabular}

\section{M\&V baseline development \\ 3.1 Overview}

Before the demand side management (DSM) activity is implemented, it is essential that the overall status of the energy demand/ consumption of the affected lighting system be captured. This status will be a reference or a baseline against which the DSM activity's energy target will be measured. The purpose of the baseline is to calculate what the energy consumption would have been without any DSM intervention.

In the pre-implementation stage, the $\mathrm{M} \& \mathrm{~V}$ Team determined the baseline through measurements. During the post-implementation stage, the baseline is then used to determine the true energy and demand savings achieved.

Adjustments can be made to the baseline when any of the original development assumptions become invalid or criteria are no longer satisfied. The general equation used for the calculation of the savings is given as:

Savings $=$ Baseline - Actual \pm Adjustments

\subsection{Baseline of case study}

The baseline for this project was determined as follows:

Step 1: The M\&V Team determined the actual power demand for each type of light that was affected by this project. This was done through spot measurements of samples representing each lighting type affected by the project. Spot measurements are on-the-spot measurements of the power demand with a hand-held power meter.

As the spot measurements were taken throughout the facility, the number of broken lights relative to the installed number of lights for a measured batch of lights was determined. At the end of the measurement exercise, the average \% breakage was determined as well as the power demand per type of light. The facility prides itself on creating a safe working environment. Therefore broken lighting is corrected immediately, which gives $0 \%$ breakage.

Step 2: The M\&V Team determined the old lighting systems installed power demand and used the verified number of lights determined by the $\mathrm{M} \& \mathrm{~V}$ team through spot checks and by the contractor who did the installation.

As all the lights are in use twenty four hours of the day the profile stays constant and does not change. This profile is shown in Figure 2. The demand per type of light, amount of each type of light and the installed capacity per type is shown in Table 2 .

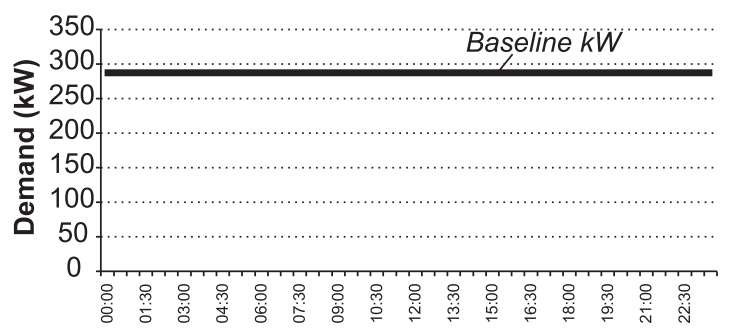

Figure 2: Daily electrical energy usage profile

Table 2: Types of lights before retrofit

\begin{tabular}{lccc}
\hline Type & $\begin{array}{c}\text { Watt per } \\
\text { type }\end{array}$ & Number & $\begin{array}{c}\text { Total } \\
\mathrm{kW}\end{array}$ \\
\hline $2 \times 8 \mathrm{ft} \mathrm{T12} \mathrm{fluorescent}$ & 138 & 853 & 117.7 \\
\hline $2 \times 5 \mathrm{ft}$ T8 fluorescent & 147 & 587 & 86.3 \\
\hline $2 \times 5 \mathrm{ft} \mathrm{T12} \mathrm{fluorescent}$ & 150 & 2 & 0.3 \\
\hline $60 \mathrm{~W}$ incandescent & 60 & 337 & 22.6 \\
\hline $100 \mathrm{~W}$ incandescent & 100 & 555 & 55.5 \\
\hline $125 \mathrm{~W}$ mercury vapour & 140 & 13 & 1.8 \\
\hline $400 \mathrm{~W}$ mercury vapour & 430 & 8 & 3.4 \\
\hline Total & 1165 & 2395 & 287.6 \\
\hline
\end{tabular}

Table 2 has more lights than Table 1 because the $\mathrm{M} \& \mathrm{~V}$ Team went into more details when doing an audit of the lighting system. After the $\mathrm{M} \& \mathrm{~V}$ team has followed all the baseline steps, they sent the baseline to the ESCO for agreement. The M\&V Team received the signed baseline agreement from the ESCO and continued with post implementation.

\section{Post implementation assessment}

The post implementation assessment is done in order to verify that the implementation has indeed taken place to specification and if there are any deviations from the original project proposal. Post metering can also be done during this stage.

\subsection{Results of post implementation}

The number of lights replaced was verified by the contractor who did the installation as well as with spot checks from the M\&V Team. A walk-through audit was done in the mine after implementation to check if all the changes had been done as proposed.

It was found that the ESCO did not replace the 
lights as proposed in Table 1. The ESCO had replaced only the $58 \mathrm{~W}$ fluorescent and $24 \mathrm{~W}$ dulux ECG as originally proposed. The ESCO did not replace the $13 \mathrm{~W} \mathrm{CFL}$ and the $80 \mathrm{~W}$ fluorescent, which were part of the proposal, but they replaced the $36 \mathrm{~W}$ fluorescent instead of the $80 \mathrm{~W}$ fluorescent and the 20W CFL instead of 13W CFL.

The ESCO did not install these lights because of the new policy and requirements from the client. These lights were out of stock at the time of implementation so the client insisted on fittings/lamps that would be easy to source once up for replacement. Table 3 shows the original lighting fixtures with the new installed lighting.

Table 3: New installed lighting fixtures

\begin{tabular}{lclc}
\hline $\begin{array}{l}\text { Original } \\
\text { type }\end{array}$ & $\begin{array}{c}\text { No of } \\
\text { tubes }\end{array}$ & $\begin{array}{c}\text { Installed } \\
\text { type }\end{array}$ & $\begin{array}{c}\text { No of } \\
\text { tubes }\end{array}$ \\
\hline 2x8ft T12-75w fluor & 853 & 2x5ft T8-58W fluor & 32 \\
\hline $60 / 100 \mathrm{~W}$ incand. & 932 & 20W CFL & 931 \\
\hline $125 \mathrm{~W}$ merc vapour & 13 & $24 \mathrm{~W}$ delux & 26 \\
\hline 2x5ft T12-65W fluor & 589 & 36 W fluor. & 2884 \\
\hline 400W merc vapour & 8 & $400 \mathrm{~W}$ merc vapour & 8 \\
\hline Total & 2395 & & 3881 \\
\hline
\end{tabular}

Now that the baseline has been developed and the installed equipment verified, the actual performance of the lighting retrofit DSM project can be determined.

\section{Performance assessment}

During performance assessment, the project is assessed on the amount of energy saved after implementation due to the DSM intervention. This was done by comparing the baseline energy use of the project with its actual energy usage after implementation. The difference is the amount of energy saved.

To determine the impact of the DSM activity, only the variables that change before and after implementation are taken into account. The post metering was done in the same manner as the pre metering. It was determined that the installed capacity of the new lighting system is $131.242 \mathrm{~kW}$ as shown in Table 4.

The contracted impact was $157 \mathrm{~kW}$ and, at the end of the project, the actual impact was $156 \mathrm{~kW}$. Therefore, the project was under-performing by $0.64 \%$ of its intended target. This was an acceptable underperformance figure. This impact is shown in Figure 3.

The average weekday demand profile was the same as the average Saturday and Sunday demand profile as the mine is operational for 24 hours daily. Since the operation of the mine is constant the impact is applicable to any time period.
Table 4: Post retrofit installed capacity

\begin{tabular}{lcccc}
\hline $\begin{array}{l}\text { New light- } \\
\text { ing types }\end{array}$ & $\begin{array}{c}\text { No of } \\
\text { fittings }\end{array}$ & $\begin{array}{c}\text { No of } \\
\text { tubes }\end{array}$ & $\begin{array}{c}\text { Measured } \\
\mathrm{kW} / \mathrm{tube}\end{array}$ & $\begin{array}{c}\text { Total } \mathrm{kW} \\
\text { installed }\end{array}$ \\
\hline 2x58W fluorescent & 16 & 32 & 0.057 & 1.824 \\
\hline 2x36W fluorescent & 781 & 1562 & 0.037 & 57.794 \\
\hline $1 \times 36 \mathrm{~W}$ fluorescent & 1322 & 1322 & 0.037 & 48.914 \\
\hline 2x24W delux-ECG & 13 & 26 & 0.025 & 0.65 \\
\hline $1 \times 20 \mathrm{~W}$ CFL & 931 & 931 & 0.02 & 18.62 \\
\hline 400W mercury vapour & 8 & 8 & 0.43 & 3.44 \\
\hline Total & 3071 & 3381 & 0.606 & 131.242 \\
\hline
\end{tabular}

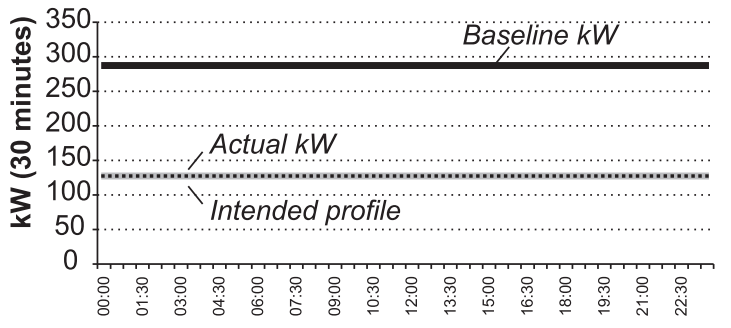

Figure 3: Average weekday demand profile

\section{Summary and conclusion}

This paper described the methodology and procedures that were followed to measure and verify the impact on the use of electricity in a lighting load reduction project implemented in a mine. It gives the details on how the baseline of the project was developed as well as the performance assessment evaluation.

The baseline determined that the installed capacity of the lighting system was $287.6 \mathrm{~kW}$. The post implementation assessment determined that the new lighting system's installed capacity was $131.3 \mathrm{~kW}$. The lights are operational for 24 hours with no breakage, and therefore, the impact of the lighting retrofit is about $156 \mathrm{~kW}$. This is $0.64 \%$ lower than the contracted target for this project.

The outcome of the project shows that it is possible to save electricity at a mine through an efficient lighting retrofit. However, the lighting used inside a mine should be readily available for maintenance purposes. These lights should also be fit to work inside a mine, and should comply with safety and electrical regulations and policies of a mine.

\section{References}

Grobler L.J. and den Heijer W., - The Measurement and Verification Guideline: 2006.

International performance measurement \& verification protocol (IPMV), 2002.

Masopoga I.M. and van der Merwe C.A., Measurement and verification reports for underground mine lighting retrofit: 2007.

Received 29 October 2007; revised 27 July 2009 